\title{
The Colon in Kwashiorkor
}

\author{
A. O. B. REDMOND, R. O. C. KASCHULA, C. FREESEMAN, and J. D. L. HANSEN \\ From the Departments of Paediatrics, Child Health and Pathology, University of Cape Town, South Africa
}

Redmond, A. O. B., Kaschula, R. O. C., Freeseman, C., and Hansen, J. D. L. (1971). Archives of Disease in Childhood, 46, 470. The colon in kwashiorkor. The colon in kwashiorkor was investigated by means of rectal biopsy and sigmoidoscopy in 20 children, followed by barium enema in 10 of the children. The colon during the acute phase of the disease showed a surface epithelial atrophy, with infiltration of plasma cells and congestion of small vessels. Viewed under the dissecting microscope, a disorganized vascular pattern was seen in all cases.

On recovery from kwashiorkor after 3 to 4 weeks, the abnormal vascular pattern and epithelial atrophy of the colon had returned to normal in most children.

Changes in the upper gastrointestinal tract, particularly in the jejunal mucosa have been noted in kwashiorkor for some time. Trowell, Davies, and Dean in 1954 first described the intestinal wall as being abnormally thin. After the introduction of the Crosby capsule (Crosby and Kugler, 1957) numerous reports of the histopathology and dissecting microscope findings appeared (Banwell, Hutt, and Tunnicliffe, 1964; Stanfield, Hutt, and Tunnicliffe, 1965; Burman, 1965; Barbezat et al., 1967). The jejunal mucosa appears flat with a few villi, and there is infiltration with lymphocytes and plasma cells.

Diarrhoea still remains one of the main problems in the management of kwashiorkor. Balance studies impress one with the severity of the diarrhoea, the average stool output often being $500 \mathrm{~g} /$ $24 \mathrm{hr}$. Investigation of the upper gastrointestinal tract has shown that these children have a normal gastric acidity (Wittmann, 1965), reduced pancreatic enzyme secretion (Barbezat, 1967a; Barbezat and Hansen, 1968), lactose malabsorption (Bowie, Barbezat, and Hansen, 1967), and Giardia lamblia infection (Barbezat, 1967b). There is however a group of children who have persistent watery diarrhoea, unaccounted for by any of the above causes. A recent report of water and electrolyte losses due to cholera in infants (Mahalanabis et al., 1970) points to the colon as the main site of potassium loss. In view of the fact that little seems to be known about the changes in the colon or rectum in proteincalorie malnutrition this study was undertaken in 20 children with kwashiorkor.

Received 26 March 1971.

\section{Subjects and Methods}

Twenty children with kwashiorkor, ranging in age from 6 to 29 months (mean 18.7 months), were studied. They all had the classical signs of kwashiorkor, being less than $80 \%$ of expected weight for age. All had oedema and most had skin lesions, apathy and irritability. Serum chemistry showed a mean albumin of $2.0 \mathrm{~g} / 100 \mathrm{ml}$. The children had sigmoidoscopy and rectal biopsy carried out on the day of admission or the day after admission, and again on clinical and biochemical recovery 3 to 4 weeks later.

Preparation of the colon before biopsy and sigmoidoscopy was not necessary as the colon was always empty. The rectal biopsy was taken from the posterior rectal wall using a Chevalier Jackson's rectal biopsy forceps (Thackrays Catalogue No. 9971) and placed in buffered formol saline. The rectal biopsy was first viewed under the dissecting microscope within 20 minutes of taking the specimen. The same biopsy was used for histopathology and stained with haematoxylin-eosin. In some instances periodic acid-Schiff and methyl green pyrronin were used in addition.

\section{Results}

Sigmoidoscopy. The striking finding after admission was the increased vascularity of the mucosa and the impression of hypotonicity and laxity of the bowel wall. The bowel wall in most children looked as if intussusception could occur easily, and in about half of the children a rectal prolapse was produced on removal of the instrument.

Dissecting microscope. Table I summarizes the appearances under the dissecting microscope on admission and again on recovery. It can be seen that in the majority of children the vascular pattern returned to normal on recovery. The appearance of the normal rectal mucosa viewed 


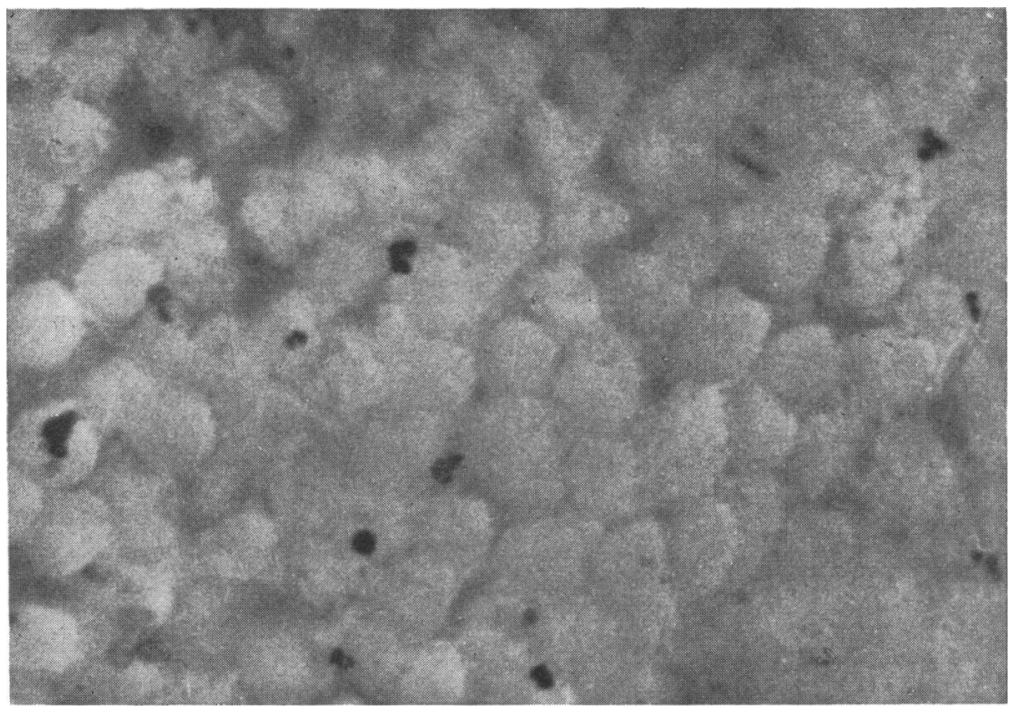

Fig. 1.-Rectal biopsy viewed under dissecting microscope on admission, showing widened vascular spaces and disorganized vascular pattern $(\times 88)$.

TABLE I

Dissecting Microscope Appearance of Rectal Mucosa

\begin{tabular}{|c|c|c|c|c|}
\hline & Admission & Recovery \\
\hline \multicolumn{3}{|c|}{ 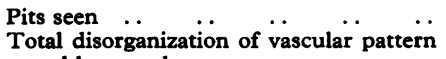 } & 0 & 14 \\
\hline and haemorrhage & . & . & 6 & 0 \\
\hline Normal vascular pattern . . & . & $\ldots$ & 0 & 13 \\
\hline Widened vascular spaces & & $\ldots$ & 10 & 6 \\
\hline Blurred vascular outline & . & . & 4 & 1 \\
\hline
\end{tabular}

under the dissecting microscope has been described by Bank et al., 1970. Fig. 1 shows a biopsy taken on admission viewed under the dissecting microscope, and demonstrates both disorganized vascular pattern and widened vascular spaces. On recovery, pits were seen in 14 children when the biopsy was viewed under oblique light (Fig. 2).

Histopathology. Histological examination of the rectal mucosa shortly after admission showed

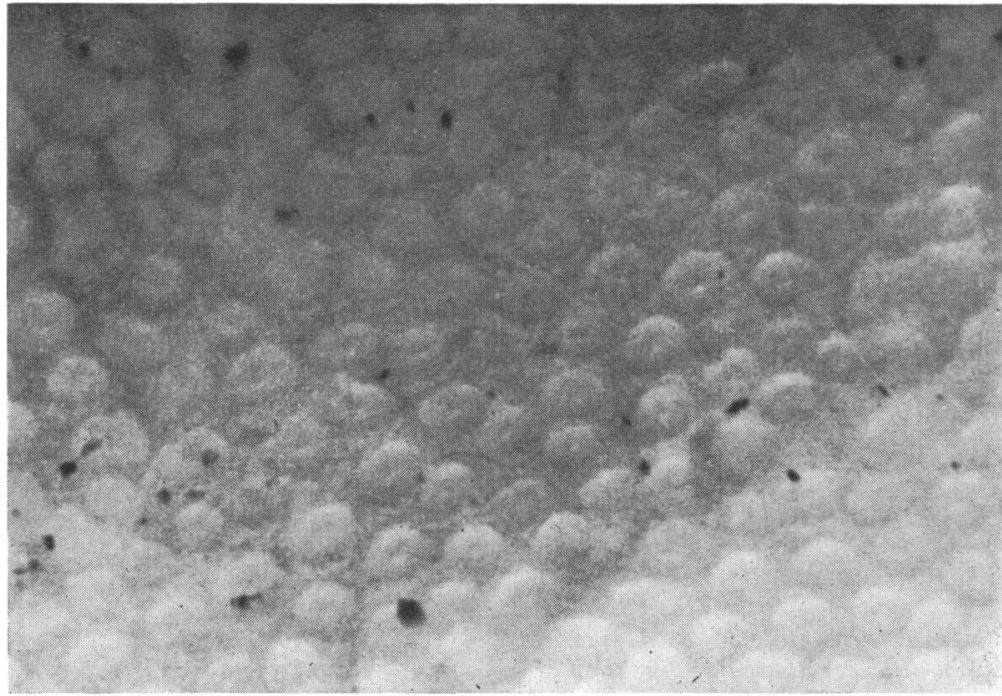

Fig. 2.-Rectal biopsy on recovery under dissecting microscope showing pits in the centre of cell units $(\times 58)$. 
features of mild atrophy (Fig. 3). The surface epithelial cells were flattened, having their normal basal nuclei relatively near the luminal surface. An appreciable reduction of mucus storage was noted in epithelial cells on the luminal surface, though goblet cells were numerous in the crypts. Polymorphonuclear leucocytes were readily seen among the surface epithelial cells. In the lamina propria the small venules and capillaries immediately below the surface epithelium were often congested. Plasma cells were uniformly seen in excessive number throughout the whole depth of the lamina propria, sometimes associated with an eosinophilia. Lymphocytes and macrophages were in normal numbers. Occasionally, oedema of the lamina propria was a striking feature producing obvious separation of crypts. Rectal biopsies taken after 3 to 4 weeks of therapy showed, in all but 6 cases, that the surface epithelial changes and congestion had reverted to normal (Table II). However, the

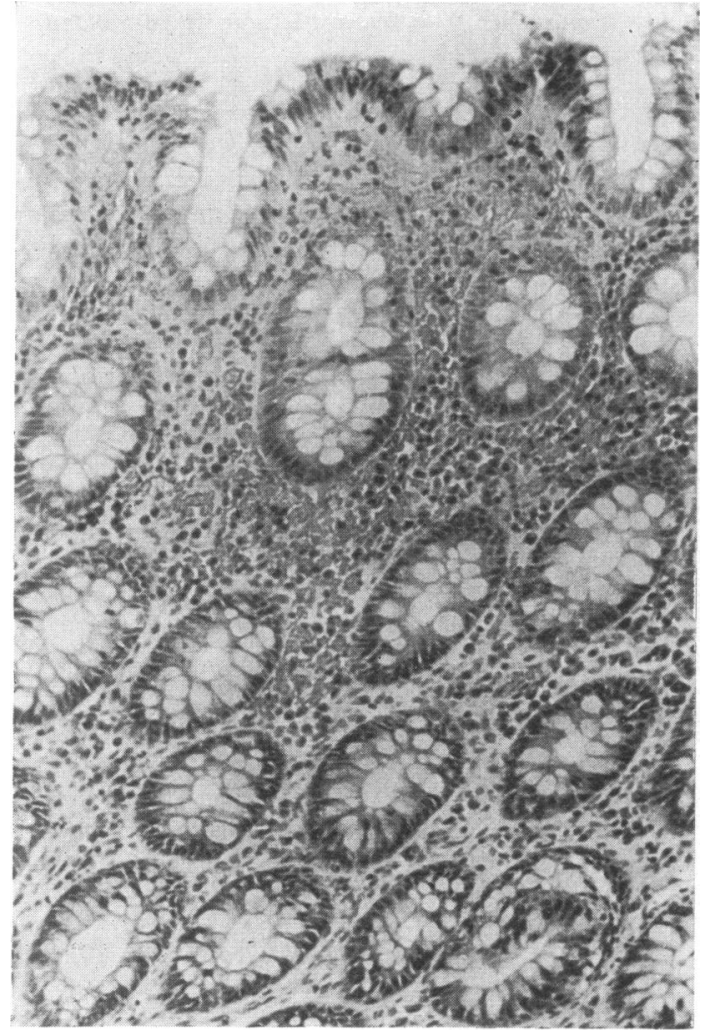

FIG. 3.-Rectal biopsy on admission. Surface epithelial cells are slightly flattened after discharge of mucus. Transepithelial migration of leucocytes with infiltration of plasma cells into the lamina propria, and congestion of superficial small vessels is evident $(\times 200)$.
TABLE II

Histology of Rectal Mucosa

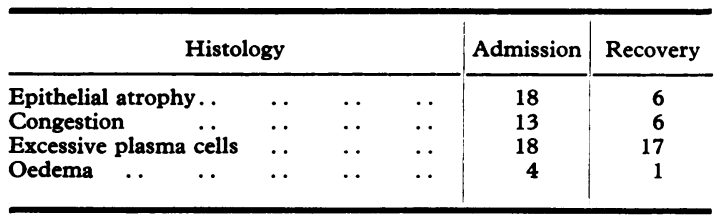

plasma cell infiltration into the lamina propria was little changed (Fig. 4).

$X$-rays. Barium enema was carried out on 10 of the children shortly after admission. No abnormality was noted, and using air contrast no changes were detectable in the mucosa. There was no delay in evacuation. These findings are in contrast to those reported by Kowalski (1967) who postulates that there is a disorder of motor function and that the autonomic nervous system is most probably responsible. Several of our children were noted to have fluid levels on straight $x$-ray of the abdomen on admission.

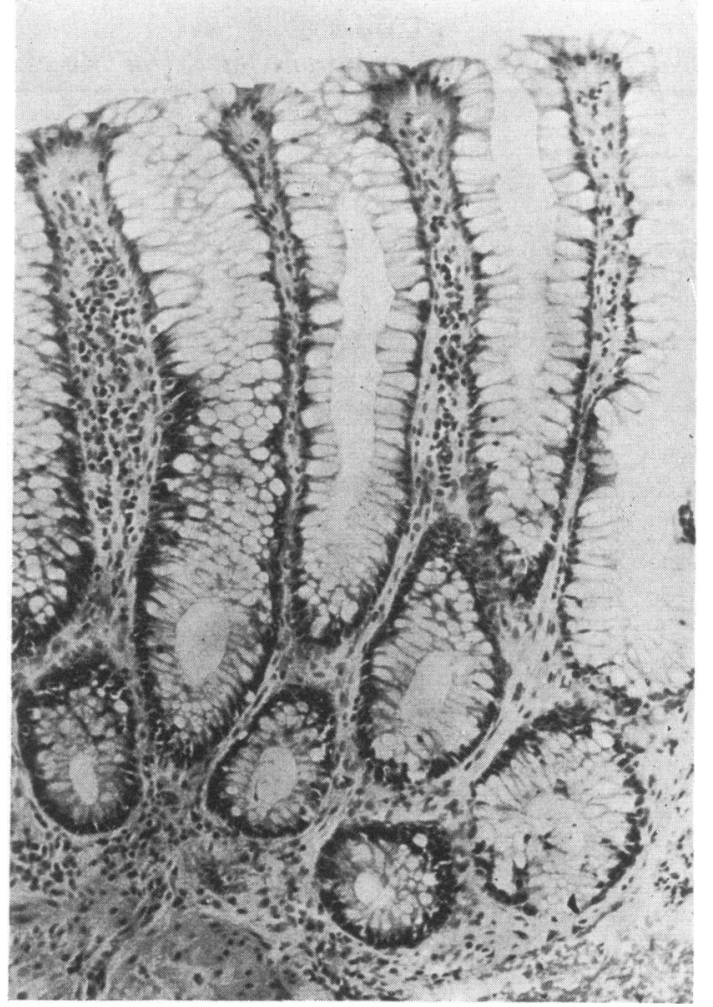

FIG. 4.-Rectal biopsy on recovery. Nuclei of surface epithelial cells are now basal. Crypts are deep. Luminal surface contains many goblet cells $(\times 180)$. 
TABLE III

Immunoglobulins $(\mathrm{mg} / 100 \mathrm{ml})$

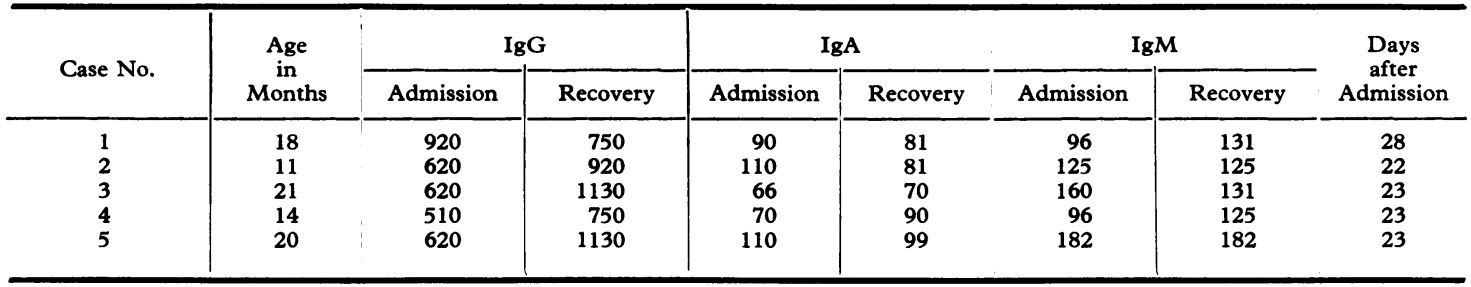

Immunoglobulins. In view of the conspicuous infiltration with plasma cells noted on admission, immunoglobulins were estimated in 5 of these children (Table III), and all had high normal levels of IgA, IgG, and IgM on admission and similar levels on recovery. High levels of IgA during the first 18 days of treatment have been noted by Keet and Thom (1969) and by Watson and Freesemann (1970). They speculate that the gut may be the first site of antigenic exposure, with early synthesis of IgA by the plasma cells. This may possibly be due to a higher bacterial count in the gut on admission and thus a higher antigenic stimulus.

\section{Discussion}

The striking findings in this study are that the colon in the acute stage of the disease shows evidence of atrophy of the surface epithelium, and increased vascularity with excessive infiltration of plasma cells. However, unlike the changes in the jejunum which have been noted to be still present after 1 year, the colon shows evidence of recovery of the mucosa in 3 to 4 weeks. It seems that both the colon and upper gastrointestinal mucosa react in a nonspecific way in kwashiorkor. The histological changes in the jejunum resemble those found in coeliac disease due to intolerance of gluten, while the colon in a treated coeliac patient given wheat enema produced changes bearing some resemblance to those seen higher up in the jejunum in untreated coeliac disease (Dobbins and Rubin, 1964). The surface epithelial atrophy, inflammatory cell infiltration, and vascular reaction seen in our cases of kwashiorkor are similar to the features of untreated coeliac disease and mild ulcerative colitis.

Perhaps these changes may account in part for the water diarrhoea and excessive potassium deficiency found in children with protein-calorie malnutrition. Since this is the first report of the changes in the colon in kwashiorkor, further studies are necessary such as pressure readings, perfusion studies and electron microscopy. These may help us to define what part the colon plays in electrolyte balance in kwashiorkor.

This work was done in the South African Medical Research Council Clinical Nutrition Research Unit at the University of Cape Town and the Red Cross War Memorial Children's Hospital. Financial assistance was provided by U.S.P.H.S. Grant AMO 3995. Thanks are due to Sisters Jolliffe and Swartz for assistance.

\section{REFERENCES}

Bank, S., Cobb, J. S., Burns, D. G., and Marks, I. N. (1970). Dissecting microscopy of rectal mucosa. Lancet, $1,64$.

Banwell, J. G., Hutt, M. S. R., and Tunnicliffe, R. (1964). Observations on jejunal biopsy in Ugandan Africans. East African Medical fournal, 41, 46.

Barbezat, G. O. (1967a). The exocrine pancreas and proteincalorie malnutrition. South African Medical fournal, 41, 84.

Barbezat, G. O. (1967b). Gastro-intestinal studies in human protein-calorie malnutrition. South African Medical fournal, 41, 1211.

Barbezat, G. O., Bowie, M. D., Kaschula, R. O. C., and Hansen, J. D. L. (1967). Studies on the small intestinal mucosa of children with protein-calorie malnutrition. South African Medical fournal, 41, 1031.

Barbezat, G. O., and Hansen, J. D. L. (1968). The exocrine pancreas and protein-calorie malnutrition. Pediatrics, 42, 77.

Bowie, M. D., Barbezat, G. O., and Hansen, J. D. L. (1967). Carbohydrate absorption in malnourished children. American Fournal of Clinical Nutrition, 20, 89.

Burman, D. (1965). The jejunal mucosa in kwashiorkor. Archives of Disease in Childhood, 40, 526.

Crosby, W. H., and Kugler, H. W. (1957). Intraluminal biopsy of the small intestine: the intestinal biopsy capsule. American fournal of Digestive Diseases, 2, 236.

Dobbins, W. O., III, and Rubin, C. E. (1964). Studies of the rectal mucosa in celiac sprue. Gastroenterology, 47, 471.

Keet, M. P., and Thom, H. (1969). Serum immunoglobulins in kwashiorkor. Archives of Disease in Childhood, 44, 600.

Kowalski, R. (1967). Roentgenologic studies of the alimentary tract in kwashiorkor. American fournal of Roentgenology, Radium Therapy, and Nuclear Medicine, 100, 100.

Mahalanabis, D., Wallace, C. K., Kallen, R. J., Mondal, A., and Pierce, N. F. (1970). Water and electrolyte losses due to cholera in infants and small children: a recovery balance study. Pediatrics, 45, 374.

Stanfield, J. P., Hutt, M. S. R., and Tunnicliffe, R. (1965). Intestinal biopsy in kwashiorkor. Lancet, 2, 519.

Trowell, H. C., Davies, J. N. P., and Dean, R. F. A. (1954). Kwashiorkor, p. 150. Arnold, London.

Watson, C. E., and Freesemann, C. (1970). Immunoglobulins in protein-calorie malnutrition. Archives of Disease in Childhood, 45, 282.

Wittmann, W. (1965). M.D. Thesis, University of Cape Town.

Correspondence to Dr. R. O. C. Kaschula, Department of Pathology, University of Cape Town, Observatory, Cape, South Africa. 